\title{
A Study on the Comprehensive Comparison between Indigenous Cattle Rustling and Modern Cattle Rustling in West Pokot County, Kenya
}

\author{
Andrew Gitau Kimani ${ }^{1}$, Casper Masiga ${ }^{1}$
}

${ }^{1}$ Kenyatta University

P. 0. Box 43844-00100, Nairobi, Kenya

DOI: $10.22178 /$ pos.65-3

JEL Classification: K40

Received 16.10.2020

Accepted 11.11.2020

Published online 31.12.2020

Corresponding Author:

Andrew Gitau Kimani

drew.kimani@gmail.com

(C) 2020 The Authors. This article

is licensed under a Creative

Commons Attribution 4.0

License @ (1)

\begin{abstract}
Evidence of change in cattle rustling practice among pastoralist communities worldwide has been noted with globalisation, education, and modernisation, among other factors. However, there is little known about transformation in men and women's involvement in this practice in the wake of easy accessibility of small and light weapons (SALWs) and breakdown of the traditional leadership and control systems. This paper examined the transformation in cattle rustling practice among the Pokot community in West Pokot county. This study's target population included adult residents of Pokot community, community elders, opinion leaders, political and administrative leaders, and local and international NGOs dealing with cattle rustling issues in West Pokot county. Multi-stage sampling technique was used to recruit 350 respondents. An unstructured questionnaire, a critical informant interview guide, a focus group discussion guide, and an observation guide were used to collect primary data. Qualitative data collected was analysed using patterns and critical themes of this particular objective. Quantitative data analysis was organised using the SPSS software version 2.0 and analysed using various descriptive statistics. The findings indicated that transformation in cattle rustling had seen a cultural activity for the young people to demonstrate their courage and wit and become a murderous criminal endeavour. The community no longer benefits from cattle rustling, but only a few are driven by greed to reap where they never sow. Illiteracy, poverty, unemployment, community conflicts, possession of firearms and insecurity were identified as the leading causes of cattle rustling. Access to formal education has seen many in the school-going age among the West Pokot get exposed to literacy, which has gradually recorded a positive transformation about its cattle rustling practices. Based on the findings, the paper makes the following recommendations to address the problem of cattle rustling among the people of West Pokot County: Enlightenment on contemporary ways of life; formal education among the Pokot to be advocated for; enhancing Security in West Pokot; opening a platform for peace talk and persuasions and operationalising the Eastern Africa Police Chiefs Cooperation Organisation (EAPCCO) protocol.
\end{abstract}

Keywords: cattle rustling; gender; cattle raids; gender transformation; transformation; raiding.

\section{INTRODUCTION}

Cattle rustling has a long history and is part of the pastoralists" culture. However, the once traditional event has acquired a new dimension in being increasingly destructive and less manageable than before. This is partly attributed to inadequate policing, acquisition of modern weapons, decline in the power of the traditional governance systems and shrinking natural resources. Initially, the focus on explaining cattle rustling's persistence was mainly cultural and ecological considerations. Cultural factors motivating cattle rustling in pastoralist societies include; belief systems, identity, warrior ideals - prestige and competition between age sets. According to [1], the transition is attributed to numerous factors. Authors [8] establishes that a cattle rustling was a cultural practice that involved traditional weapons, including spears, arrows, and sticks to steal cattle from neighbouring communities in early days. In the early days, nomadic pastoralists such as the Pokot would move freely in search of 
pasture and water moving to the highlands during the dry season and back to the plains when it rained. Being pushed to less arable lands set off long-lasting strife for resources such as water and grazing land whose effects remain adamant to date.

Traditionally, cattle rustling was a kind of organised sport and had to be sanctioned and blessed by elders [2]. Traditional values, including high bridewealth and ceremonies like sapana, which could be equated as a coming-out-to-the-community-ceremony, were identified as some of the cattle rustling motivators. Cattle raids were mainly a means for low-income families to acquire wealth and cattle. In the traditional context, cattle rustling was practised primarily to restock herds that had been rustled, or decimated by disease outbreaks or severe drought. They used conventional weapons, spears, sticks, bows and arrows to acquire livestock from another community. Livestock held a central position among the Pokot community. The study established that customs or traditional values greatly influenced people's involvement in cattle rustling based on interviews conducted, $40 \%$ explained that traditional values had very minimal impacts on the people's decisions to participate in running the cattle raiding activities.

Recently cattle rustling has evolved into large scale operations involving taking away thousands of cattle done in daylight and involving the exchange of gunfire, rape, abduction, wounding and killing of men, women and children and cattle market networks [4]. Education, religion and government legislation were said to have contributed much to this transformation. New cattle rustling is characterised by; the availability of guns, commercialisation of cattle raids, political incitement, poverty, loss of traditional values and illiteracy. Due to the proliferation of small arms and commercialisation of cattle rustling, there is an emergence of large-scale violent cattle raiding between neighbouring pastoral communities. This militarised practice seems well funded and coordinated [3]. Modern-day cattle rustling is radical and organised by anyone (including wealthy businesswomen and brokers) who have no resolve for principles and the cultural safeguards that sustained the past practice. These 'cattle warlords' are a modern cartel of financiers who through their financial strengths, have assisted in spreading this 'business of death.'

\section{METHODOLOGY}

Study Design. The study adopted a descriptive survey design that allowed the researcher to gather information summarise, present and interpret it to derive the required information. The research design also facilitated using a questionnaire, interview guide and observation to collect both quantitative and qualitative data for the study as discussed below.

The questionnaire was the primary tool used in the study. It had both closed and open-ended questions. It was administered to most of the targeted population, including, adults aged 18-35 who could read and write.

Key informants interview (KII) included the County Commissioner, the Deputy County Commissioners, the National Police Commanders, representatives of NGO and civil society. An essential informant guide was developed and used.

The focus group discussion guide (FGD) was arranged according to gender and age. All respondents were of legal age. The information elicited using this tool was on the historical organisation of the Pokot, their culture, perception of cattle rustling, the role of elders, men, youth and preparations, and processes of carrying out a successful rustling then and now.

An observation guide was developed to observe different aspects under investigation directly.

The research used various combinations of sampling methods. Multi-stage sampling was applied in the identification of the specific areas for collecting data. The selection was made at the $\mathrm{Na}$ tional Government administrative units: subcounty, division, location and sub-location.

The research generated a lot of qualitative and quantitative data. The analysis was aided by the SPSS software version 2.0, which produced various quantitative statistics. The collected data was also analysed through descriptive and inferential statistics.

\section{RESULTS AND DISCUSSION}

Demographic Characteristics of the Pokot Community. Demographic information provides insight into the main characteristics of the study population. This study's findings examined the bio-data considered to have a meaningful influence on patterns and systems that have shaped gender transformation in cattle rustling practice 
in West Pokot. Therefore, the variables, including gender, ethnic community or clan, religion, education level, marital status, age, and livelihood source, are considered.

Gender. Findings from the study indicated that men constituted the largest proportion of participants. As shown in table $175.45 \%$ of the participants were men, while only $24.55 \%$ were women. The researcher observed that women were significantly underrepresented.

Table 1 - The response rate

\begin{tabular}{|l|c|c|c|c|}
\hline & FGDs & KIIs & Total & $\%$ \\
\hline Men & 10 & 6 & 126 & 75.45 \\
\hline Women & 8 & 3 & 41 & 24.55 \\
\hline Total & 18 & 9 & 167 & 100 \\
\hline
\end{tabular}

From table 1, it can be depicted that there were fewer women in cattle rustling than men. The variance in men and women's roles explain the wide gap between men and women's participation in the study.

A significant problem is the low status of one gender in pastoral societies is because women have no inheritance right, and are isolated from decision-making concerning them directly or indirectly. They have deemed property and are engendered from early ages to respect any male authority and submit to them [2]. The data provides evidence that both men and women had different roles in using cattle obtained from raids.

Religion. According to table 2, a majority of the respondents, (94.3\%) ascribed to the Christian faith,
Muslim (3.6\%) and Traditionalist (2.1\%); which gradually replaced the traditional theology that was practised by the ancestors.

Table 1 - Religion's structure

\begin{tabular}{|l|r|r|r|r|}
\hline Religion & Men & Women & Total & $(\%)$ \\
\hline Christian & 105 & 27 & 132 & 94.3 \\
\hline Muslim & 3 & 2 & 5 & 3.6 \\
\hline Traditionalist & 2 & 1 & 3 & 2.1 \\
\hline Grand Total & 110 & 30 & 140 & 100 \\
\hline
\end{tabular}

In West Pokot, religiosity has grown since the 1960s with most people who ascribed to traditional beliefs converting to Christianity and other religions. This was as a result of translating the new testament into the local language. It was observed that in this region, men were more religious than women. This study finds that women are more devout globally by several standard religious commitment measures based on these wide-ranging and comprehensive datasets. After the introduction and set-up of missionary schools and churches in the region, many community members who embraced Christianity encouraged their children to get a formal education and shun the cattle raiding culture.

Education Level. Only $12.9 \%$ of the participants had attained a university degree, as presented (figure 1). A majority of the participants attested to having a primary or secondary certificate as their highest academic certification level, which was not the case about half a century ago.

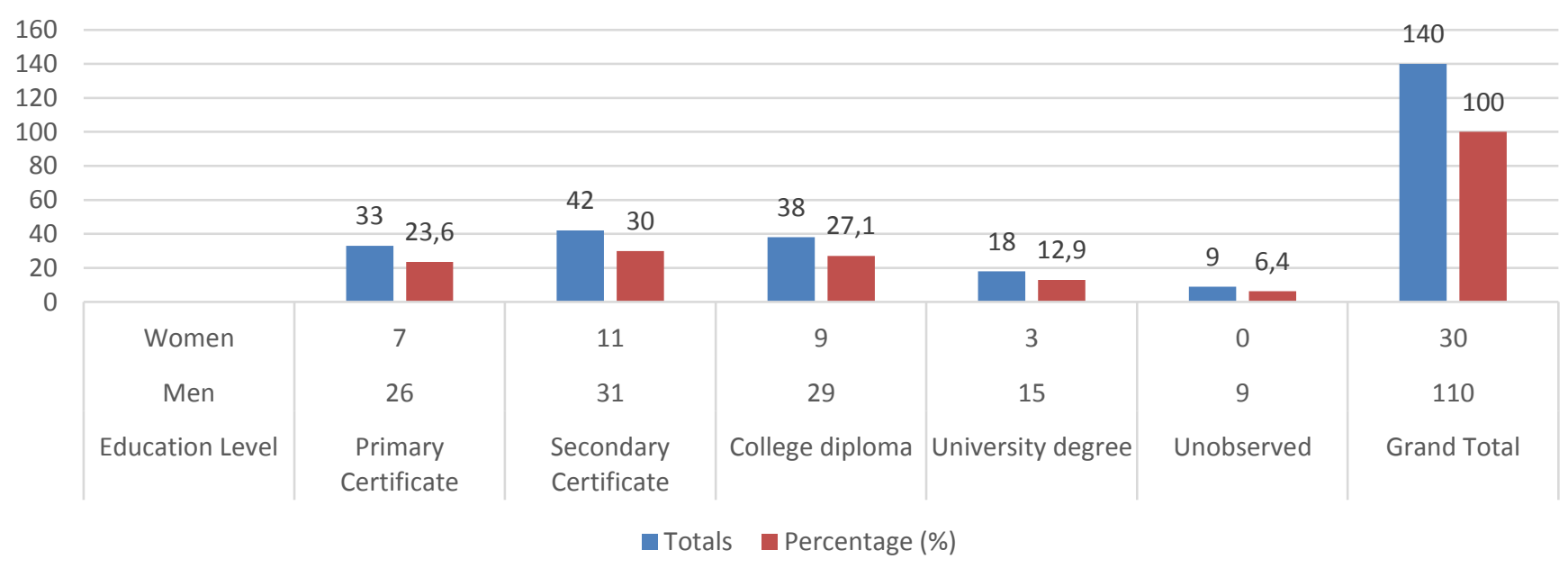

Figure 1 - Education Level 
Education has played an important role in gender transformation in cattle rustling practice. Some author associates education with modernity and change of perspective in men and women's roles in the community. Through education, West Pokot communities have become illuminated on wealth accumulation issues primarily due to contact with other modernised organisations.

According to figure 2, the primary source of livelihood among the Pokot is pastoralism; however, they have been observed to have alternative livelihood sources in recent times.

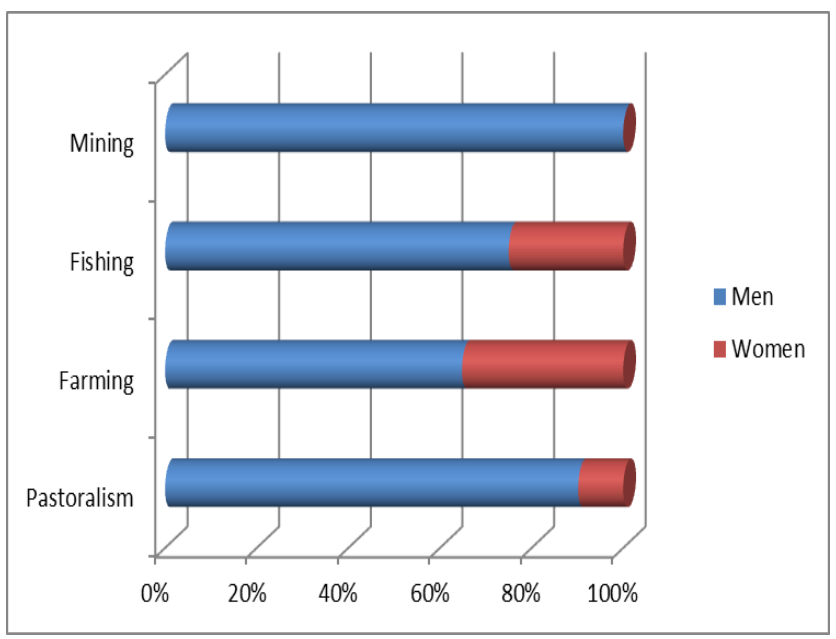

Figure 2 - Source of Livelihood

This is includes farming, fishing and mining. According to FAO, increasing El-Nino and climate change effects has grown and made droughts more widespread and severe. FAO points out that "drought-hit pastoralists face reduced milk production, rising malnutrition and have the limited income-earning capacity and severely constrained access to food." Alternatives to keeping livestock such as growing drought-resistant crops are being seen as the panacea. Sorghum, wheat and chillies are being introduced as alternates and touted as game-changers (AGRA). Galvin (2009:193) states that "As pastoralists become sedentary, cultivate and diversify their livelihoods, the move to increase control over land becomes understandable.

\section{Factors accelerating cattle rustling practice in West Pokot}

Many authors observe that new cattle rustling is violent and deadly, accounting for the loss of many lives and property destruction. Besides, rustlers use sophisticated and lethal weapons to kill and scare away the owners before making off with the livestock. Consequently, modern-day cattle rusting constitutes a menace that impedes development and peace restoration efforts in various pastoral communities. Based on the analysis of the interviews and observations, the main factors that caused explosive and violent cattle raiding were categorised as follows: the availability of guns and other types of dangerous weapons among Pokot members. The majority of the respondents considered ease of access to firearms and other weapons to be the leading cause of the intense frequency of cattle raids [3].

The subsequent commercialisation of cattle raids, a modern means for criminals to acquire wealth and cattle is prevalent. Perpetrators engage in the practice for a wide range of reasons, many of which aim to profit only small groups of criminals or bandits. The high premium placed on livestock and the increasing cost of beef and animal product in cities fuels the cattle trade today. For instance, cows stolen are traded for guns and munitions or money. Patterns of contemporary cattle rustling observed in West Pokot contradict the traditional setting that often-involved small- scale violence and theft of the best livestock or replacement or restocking of animals lost through drought or disease accumulation of wealth.

Thirdly, incitement from the political leaders, the cultural leaders and self-serving business people was cited by interview participants as another leading cause of cattle raids. Out of all interviewees' responses, most of them explained that the community leaders and political leaders are at the forefront of instigating and inciting the healthy youths to participate in cattle raids. While cattle raids in the past were conducted for the benefit of the clan or community, modern trends indicate that most people steal cattle for their individual, political and economic gain. Some author observes that livestock plays essential and multiple roles in pastoralists' lives in that it is their mainstay, socially and economically. It is a means to store wealth, pay dowry and other customary ceremonies, compensation, a sign of prestige and pride, respect, business prowess, among others. In this respect, owning livestock became a lucrative and consequently dangerous venture as their mobility and transferability, making them easy targets. The continued link between cattle and culture makes pastoralists have no other means to survive as the ownership, continued production, and livestock management is their raison-d etre 
(Ibid). The large cattle owners use a quasi-communal individualism to perpetuate cattle's continual and beneficial importance above other aspects, including education. This is ensured a continued supply of labour and herdsmen and increased herd size without concern to the animals' welfare.

The findings recorded high poverty rates and the need to accumulate wealth, traditional values and a long history of cattle raiding encouraged by the community leaders, high rates of illiteracy and increasing dowries as other critical drivers of cattle rustling.

The study also discussed different aspects of the evolvement of cattle rustling, as shown in table 3.

Table 3 - Transformation of cattle rustling

\begin{tabular}{|l|c|c|c|c|}
\hline The aspect of change or & \multicolumn{2}{|c|}{ Frequency } & \multicolumn{2}{|c|}{$\%$} \\
\cline { 2 - 5 } evolvement & Yes & No & Yes & No \\
\hline $\begin{array}{l}\text { Cattle rustling has become } \\
\text { more frequent }\end{array}$ & 70 & 70 & 50 & 50 \\
\hline $\begin{array}{l}\text { It takes a short time to } \\
\text { accomplish a task }\end{array}$ & 100 & 40 & 71 & 17 \\
\hline $\begin{array}{l}\text { More rustlers are involved } \\
\text { than previously }\end{array}$ & 65 & 75 & 46 & 54 \\
\hline $\begin{array}{l}\text { Guns are used more than } \\
\text { spears or arrows }\end{array}$ & 28 & 112 & 80 & 20 \\
\hline $\begin{array}{l}\text { More people are killed in } \\
\text { cattle raid than before }\end{array}$ & 130 & 10 & 93 & 7 \\
\hline $\begin{array}{l}\text { The number of people } \\
\text { injured in a cattle raid is } \\
\text { higher }\end{array}$ & 124 & 16 & 89 & 11 \\
\hline $\begin{array}{l}\text { The number of cattle taken } \\
\text { is higher today than } \\
\text { previously }\end{array}$ & 115 & 25 & 82 & 18 \\
\hline $\begin{array}{l}\text { Today no cattle are left } \\
\text { behind for the herd owner } \\
\text { to start off }\end{array}$ & 125 & 15 & 89 & 11 \\
\hline $\begin{array}{l}\text { Houses are burnt during } \\
\text { cattle rustling today }\end{array}$ & 130 & 10 & 93 & 7 \\
\hline $\begin{array}{l}\text { Children are killed during } \\
\text { cattle rustling today }\end{array}$ & 123 & 17 & 88 & 12 \\
\hline $\begin{array}{l}\text { Elders always sanction } \\
\text { cattle rustling today }\end{array}$ & 7 & 133 & 5 & 95 \\
\hline $\begin{array}{l}\text { Mothers always bless their } \\
\text { sons before they go for } \\
\text { cattle rustling }\end{array}$ & 29 & 111 & 21 & 79 \\
\hline $\begin{array}{l}\text { Cattle rustled is always } \\
\text { shared with those who did } \\
\text { not participate }\end{array}$ & 5 & 135 & 4 & 96 \\
\hline Agregate mean & 81 & 59 & 63 & 37 \\
\hline
\end{tabular}

The table presents some of the new things now characteristic of Modern-day cattle rustling - aspects of Evolvement of Cattle Rustling ( $\mathrm{N}=284)$.

Findings on transformation in cattle rustling practices presented in table 3 show that most of the respondents (63\%) agreed that there had been significant changes in cattle rustling practices among the Pokot community. At the same time, about one third answered on the contrary. Most of the respondents (93\%) further agreed that more people are killed houses are burnt during cattle rustling today than before. The respondents answered that there is no sharing of cattle rustled with those who did not participate in the raid.

From the survey data presented, it's evident that cattle rustling practice has changed over time.

\section{CONCLUSIONS}

The findings indicated that transformation in cattle rustling had seen a cultural activity for the young people to demonstrate their courage and wit and become a murderous criminal endeavour. The community no longer benefits from cattle rustling, but only a few are driven by greed to reap where they never sow. Illiteracy, poverty, unemployment, community conflicts, possession of firearms and insecurity were identified as the leading causes of cattle rustling. Access to formal education has seen many in the school-going age among the West Pokot get exposed to literacy, which has gradually recorded a positive transformation about its cattle rustling practices.

The paper makes the following recommendations to address the problem of cattle rustling among the people of West Pokot County: Enlightenment on contemporary ways of life; formal education among the Pokot to be advocated for; enhancing Security in West Pokot; opening a platform for peace talk and persuasions and operationalising the Eastern Africa Police Chiefs Cooperation Organisation (EAPCCO). Intermarriages were also seen to be an effective way to reduce cattle rustling. Construction of integrated border schools with specific and targeted recruitment of schoolgoing children from all the warring communities, including holiday exchanges was also an effective way of reducing this cattle rustling incidence.

However, the study highly recommends that one of the most effective methods to reduce new cattle rustling in those prone areas is a paradigm shift to livestock ownership. This mindset will 
incorporate the introduction of non-gender economic activities that will supplement or replace ownership of livestock as a measure of financial wealth and store. Concerted efforts in infrastructural development by the Government and other stakeholders, will significantly bring the muchneeded product to this arid and barren lands and spur growth and other industries, including mining and irrigation.

\section{REFERENCES}

1. Byrne, S., Carter, N., \& Senehi, J. (2001). Social Cubism and Social Conflict: Analysis and Resolution. Journal of International \& Comparative Law, 8(3), 725-740

2. Cheserek, G. J., Odenyo, V. A. O., \& Omondi, P. (2012). Nature and causes of cattle rustling among some pastoral communities in Kenya. Journal of Emerging Trends in Economics and Management Sciences, 3(2), 173-179.

3. Gumba, N., Alusala, N., \& Kimani, A. (2019). Vanishing herds. Cattle rustling in East Africa and the Horn. Retrieved from https://enact-africa.s3.amazonaws.com/site/uploads/2019-12-18vanishing-herds-research-paper-10.pdf

4. Mkutu, K. (2008). Disarmament in Karamoja, Northern Uganda: Is This a Solution for Localised Violent Inter and Intra-Communal Conflict? The Round Table, 97(394), 99-120. doi: $10.1080 / 00358530701844718$

5. Mkutu, K. A. (2006). Small arms and light weapons among pastoral groups in the Kenya-Uganda border area. African Affairs, 106(422), 47-70.

6. Schilling, J., Akuno, M., Scheffran, J., \& Weinzierl, T. (2012). On arms and adaptation: Climate change and pastoral conflict in Northern Kenya. Retrieved from https://www.researchgate.net/publication/263242776_On_arms_and_adaptation_Climate_chan ge_and_pastoral_conflict_in_Northern_Kenya

7. Schilling, J., Opiyo, F. E., \& Scheffran, J. (2012). Raiding pastoral livelihoods: motives and effects of violent conflict in north-western Kenya. Pastoralism: Research, Policy and Practice, 2(1), 25. doi: 10.1186/2041-7136-2-25

8. Skoggard, I. \& Adem, T. A. (2010). From raiders to rustlers: The filial disaffection of a Turkana ageset. Ethnology, 49(4), 249-262. 